\title{
The role of syllables in sign language production
}

\author{
Cristina Baus $^{1 *}$, Eva Gutiérrez ${ }^{2}$ and Manuel Carreiras ${ }^{3,4,5}$ \\ ${ }^{1}$ Laboratoire de Psychologie Cognitive, Centre National de la Recherche Scientifique (CNRS), Université d'Aix-Marseille, Marseille, France \\ 2 Deafness, Cognition and Language Research Centre, University College London, London, UK \\ ${ }^{3}$ BCBL - Basque Research Center on Cognition, Brain and Language, Donostia, Spain \\ ${ }^{4}$ IKERBASQUE, Basque Foundation for Science, Bilbao, Spain \\ ${ }^{5}$ Departamento de Lengua Vasca y Comunicación, Universidad del País Vasco, Donostia, Spain
}

\author{
Edited by: \\ Iris Berent, Northeastern University, \\ USA \\ Susan Goldin-Meadow, University of \\ Chicago, USA \\ Reviewed by: \\ Ariel M. Cohen-Goldberg, Tufts \\ University, USA \\ Marie Coppola, University of \\ Connecticut, USA \\ ${ }^{*}$ Correspondence: \\ Cristina Baus, Laboratoire de \\ Psychologie Cognitive, Centre \\ National de la Recherche \\ Scientifique (CNRS), Université \\ d'Aix-Marseille, 3, Place Victor Hugo, \\ 13331 Marseille, France \\ e-mail: baus.cristina@gmail.com
}

The aim of the present study was to investigate the functional role of syllables in sign language and how the different phonological combinations influence sign production. Moreover, the influence of age of acquisition was evaluated. Deaf signers (native and non-native) of Catalan Signed Language (LSC) were asked in a picture-sign interference task to sign picture names while ignoring distractor-signs with which they shared two phonological parameters (out of three of the main sign parameters: Location, Movement, and Handshape). The results revealed a different impact of the three phonological combinations. While no effect was observed for the phonological combination Handshape-Location, the combination Handshape-Movement slowed down signing latencies, but only in the non-native group. A facilitatory effect was observed for both groups when pictures and distractors shared Location-Movement. Importantly, linguistic models have considered this phonological combination to be a privileged unit in the composition of signs, as syllables are in spoken languages. Thus, our results support the functional role of syllable units during phonological articulation in sign language production.

Keywords: sign language, speech production, syllables, sign parameters, picture naming

\section{INTRODUCTION}

In recent years, research on sign language has accumulated evidence to suggest that spoken and sign languages are governed by similar cognitive mechanisms and underpinned by similar neuroanatomical substrates. For instance, the existence of the same linguistic phenomena in both modalities has been taken as evidence that levels of linguistic processing (semantic, lexical, and phonological) are modality-independent. The same semantic, lexical, and phonological effects reported in the spoken modality have been replicated in the sign modality (e.g., Emmorey and Corina, 1990; Corina and Knapp, 2006; Baus et al., 2008; Carreiras et al., 2008; Gutierrez et al., 2012a,b; Hosemann et al., 2013; see Carreiras, 2010 for a review). Furthermore, the same left-lateralized brain network has been described to underlie the processing of signed and spoken languages (e.g., San JoseRobertson et al., 2004; Emmorey et al., 2007; see also MacSweeney et al., 2008 for a review).

Signs, as well as words, can be decomposed into minimal phonological constituents or formational parameters (Emmorey, 2002; but see Johnston and Schembri, 1999). Three have been considered the main formational parameters of signs (Stokoe, 1960): the Location of the sign in relation to the body, the Movement of the hand/s and the Handshape. Importantly, different studies suggest that these parameters play a different role during language processing (see also current phonological models in sign language; e.g., Brentari, 1998). For instance, using a picture-sign interference task, Baus et al. (2008) reported that lexical access was facilitated when the sign corresponding to the picture and the distractor-sign shared the Handshape, while it was hampered when the Location was shared (see also, Corina and Hildebrandt, 2002; Carreiras et al., 2008; Gutierrez et al., 2012b, for similar results in sign comprehension; see Caselli and Cohen-Goldberg, 2014, for a computational model). Despite the importance of these results, sign production research is still very scarce and hence more evidence is necessary to characterize the role of these phonological parameters and the possible interactions among them. In the present study, we aimed to understand better the processes underlying sign production by asking whether phonological constituents (Location, Movement, and Handshape) are combined into higher order units before a sign is articulated, as phonemes are combined into syllables in spoken languages. To that end, the impact of the different combinations of phonological parameters on sign production was explored.

In spoken languages, syllables are considered the functional units during speech planning (e.g., Levelt and Wheeldon, 1994; Carreiras and Perea, 2004; Cholin et al., 2006; Laganaro and Alario, 2006). Accordingly, models of speech production describe the locus of syllables within the production system, either at the word-form encoding level (phonological syllables, see Dell, 1988) or during articulatory preparation (e.g., Crompton, 1981; Levelt and Wheeldon, 1994). Experimental evidence for the existence of syllables in speech production comes from different sources, such as speech errors or syllabic effects. For instance, it has been 
shown that speech errors respect the syllable position constraint (e.g., Boomer and Laver, 1968; Mackay, 1970). That is, for those sound/form exchanges occurring between close-by words (such as rack pat for pack rat), onsets are exchanged with onsets but not with codas. Moreover, the role of syllabic units in word production has been explored mainly through two effects: the so-called syllabic frequency effect and the syllabic priming effect. The syllabic frequency effect refers to the observation that speakers are faster at naming words (and pseudowords) containing high frequency syllables than low frequency ones (e.g., Levelt and Wheeldon, 1994; Aichert and Ziegler, 2004; Alario et al., 2004; Carreiras and Perea, 2004; Cholin et al., 2006; Laganaro and Alario, 2006). The syllabic-priming effect refers to the observation that speakers are faster at naming a word (e.g., basis) when it has been primed with a syllable (ba) that respects the syllable boundaries of the word, than with an incongruent syllable (bas) that does not respect such boundaries (e.g., Ferrand et al., 1996, 1997; but see, Baumann, 1995; Schiller, 1998; Schiller et al., 2002; Schiller and Costa, 2006, for failed attempts to replicate the syllabic priming effect).

Linguistic theories of the structure of signed language agree on the existence of such syllabic-like units in signed language. That is, the syllable as a formal concept has an analog in signed language. The parallelism between syllables in spoken and signed languages stems from the idea that the way phonological constituents are organized into syllables depends on the sonority of the segments (Perlmutter, 1992). Signs are sequentially organized in terms of static-dynamic alternation that could be compared to consonants (holds) and vowels (movements) in the spoken modality. Syllables must include a nucleus, which corresponds to the maximal peak of sonority, the vowel, and may include an onset or a coda (Selkirk, 1982). The same applies to sign language. Models of sign language tend to attribute to the Movement the status of the nucleus (e.g., Chinchor, 1978; Brentari, 1990; Corina, 1990; Sandler, 1993; Brentari, 1998). In fact, Sandler's LocationMovement-Location model (Sandler, 1987, 1989) proposes that it is the combination of Locations and Movements that composes a syllable (see Chinchor, 1978; Wilbur, 1993, for a fairly different view). Indeed, the Movement is considered the visual equivalent of "sonority," being then the most salient parameter, which can be easily differentiated from the other parameters. For instance, as do vowels in the spoken modality, Movements in a sign carry prosodic as well as emotional information. Moreover, for some signs, the number of Movement repetitions determines whether a given sign is a noun or a verb (e.g., GLASS and TO DRINK in LSC have the same C Handshape next to the mouth with one repetition of the sign glass and two for to drink). Importantly however, as indicated by Emmorey et al. (2007), the fact that words and signs can be decomposed into similar syllabic-units is not a guarantee that syllabification processes are the same in word and sign production. There are several differences between spoken and signed languages that could contribute to the suggested difference in processing (for instance, most signs are monosyllabic, Brentari, 1990). Indeed, the same happens if we consider the role of syllables across different spoken languages. For instance, while syllables exist across languages, their impact as segmentation units is stronger for those languages with clear syllabic boundaries (e.g., Romance languages). Moreover, planning units might vary depending on the task in hand. In Chinese, while syllables are the functional unit during speech production (Chen et al., 2002), logographemes are the proximal unit in handwritten production (Chen and Cherng, 2013). Thus, even if syllables have been linguistically described in signed language, it is important to describe their psychological reality by exploring how signers process these syllabic units in sign language (see Corina et al., 2014).

To date however, the functional role of syllables in sign language processing has scarcely been investigated (Corina and Knapp, 2006; Dye and Shih, 2006; Mayberry and Witcher, 2006; Gutierrez, 2008). Interestingly, these few results point to a special status of the combination of Location-Movement in both sign comprehension and production. For instance, Dye and Shih (2006) tested the speed with which deaf signers took lexical decisions in a priming paradigm in which primes and targets shared two out of the three phonological parameters (Location, Handshape, and Movement). Their results revealed that native deaf signers were faster at making decisions on the target, exclusively when prime and target shared Location and Movement. Similarly, Corina and Knapp (2006) reported a facilitatory effect for the combination Location-Movement in ASL sign production using a picture-sign interference task. However, although these results provide evidence of the privileged status of this phonological combination in sign production, they remain silent about the role of the other phonological combinations. Thus, the present study aimed to further investigate how the different combinations of parameters, namely Location-Movement, Location-Handshape and Handshape-Movement affect the speed with which signs are produced.

Our second aim was to expand Corina and Knapp's results (2006) by exploring the influence of age of acquisition on the processing of these syllabic-like units. Age of acquisition is a very interesting issue to address here, since signed language offers the unique opportunity to test age of acquisition differences in first language processing. Several studies have reported differences in performance between signers who acquire a sign language early relative to those who acquire sign language later in life (Mayberry and Fisher, 1989; Newport, 1990; Corina and Hildebrandt, 2002; Carreiras et al., 2008; Gutierrez et al., 2012a). Such differences have been attributed to a "phonological bottleneck" by which the form-based properties of signs are processed less efficiently the later the sign language is acquired. For instance, in Dye and Shih (2006), no phonological effect was observed for the LocationMovement combination when non-native signers were tested in the priming experiment. Instead, priming effects arose uniquely when primes and targets shared the Movement parameter in isolation. To further explore how age of acquisition influences lexical access during sign production, we compared the performance of two groups of signers that differed in the age at which sign language was acquired. The hypothesis is that if non-native signers are less efficient in processing phonological units in sign language, it is possible that the different phonological combinations do not equally impact native and non-native processing.

In the present study we used a picture-sign interference task (Corina and Knapp, 2006; Baus et al., 2008) and asked deaf signers who had acquired the signed language early (born within 
deaf families) or late (after the age of 10) to sign the corresponding picture-sign while ignoring a distractor. The task was an adaptation of the picture-word interference paradigm, which has been extensively used in the language production literature to reveal the functional dynamics of lexical retrieval processes in speech production. Note that this is not to say that comprehension mechanisms are not involved in the processing of the distractors.

\section{METHODS \\ PARTICIPANTS}

Twenty-four deaf signers participated in this study (11 women). The participants were the same as in Baus et al. (2008). All of them were deaf from birth and used Catalan Sign Language (LSC) on a daily basis as preferred means of communication. Twelve participants were considered as native signers (age range 18-51, mean age $30.3, S D=7.6$ ). They were born in deaf families (parents or older siblings) and acquired the signed language before the age of 5. The remaining were non-native signers (from hearing families) (age range $18-44$, mean age $26.4, S D=5.8$ ) who learned LSC at the mean age of 12 (age of exposure range 10-31 years, mean = $16, S D=7.2$ ). Both groups of participants had attended "oralist" schools (it is relatively new to find schools adapted to the deaf community). All of them had completed the years of compulsory education (primary school, up to 14 years old), with only a few of them completing the secondary levels of education (5 participants). All participants reported feeling more comfortable using the signed than the spoken language.

\section{MATERIALS}

Thirty line-drawings depicting simple objects from different semantic categories were selected (e.g., Snodgrass and Vanderwart, 1980). For each picture, two video-signs (distractors) were created: one phonologically related and one unrelated. In the phonologically related condition, the sign corresponding to the picture and the distractor-sign shared two out of the three main parameters. Thus, there were three types of phonological overlap: Handshape-Movement, Location-Handshape, and Location-Movement (ten items per condition). Given that the pool of picturable stimuli is limited, it was not possible to pair each picture-sign with a distractor-sign of each phonological condition. Thus, each picture was assigned to just one of the phonological conditions and was paired with one phonologically related and one phonologically unrelated distractor. In the unrelated condition, the picture's corresponding sign and the video-sign had no phonological or semantic relationship.

During the experiment, participants saw each picture twice, once in a phonologically related pair and once in an unrelated pair. The order of appearance was randomized. The results were then based on the comparison between the related and the unrelated conditions, where the same picture was used (see Figure 1 for an example and the Appendix for the full list of materials in the Supplementary Material) and not on the comparison between the different phonological combinations. The pictures appeared superimposed on a video of a deaf person signing and were presented to participants at the same time (SOA 0).

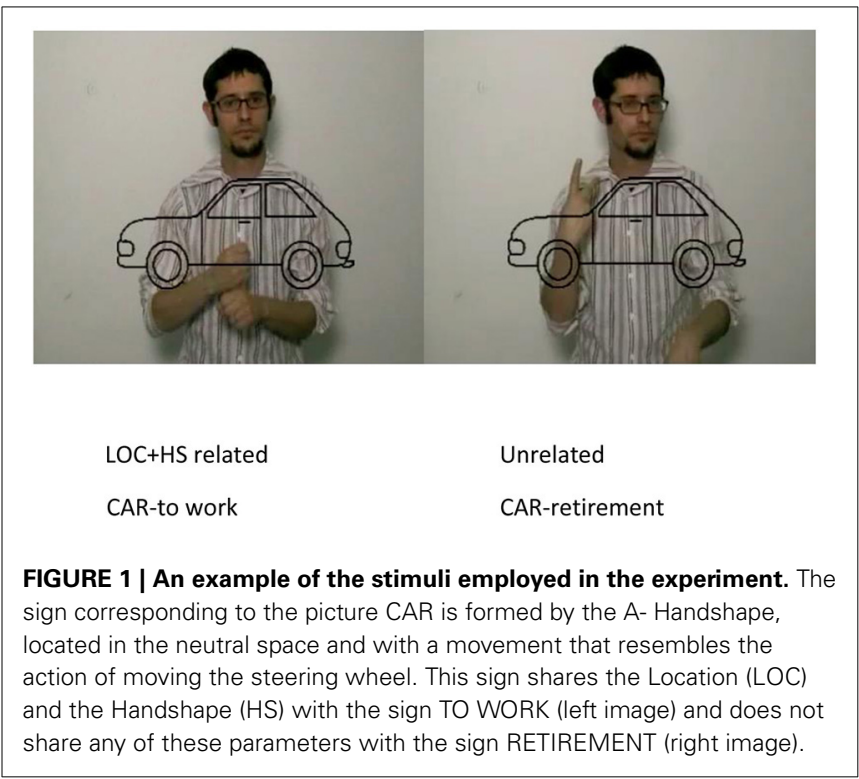

All videos had an approximate duration of $500 \mathrm{~ms}$ and comprised both the video distractor and the picture, that is, the picture appeared simultaneously with the onset of the distractor video sequence and remained visible on the screen together with the last frame of the video distractor until participants responded.

\section{PROCEDURE}

Participants were tested in a quiet room, avoiding visual distractors. Before the experiment started, instructions were signed to the participant in LSC. They were instructed to sign the name of the picture while ignoring the video presented at the back. After ensuring that participants understood the instructions, they were presented with a booklet containing all the pictures of the experiment to ensure that they used the designated sign during the experiment. Participants were then familiarized with the task in 10 practice trials with similar characteristics to the experimental ones.

During the experiment, the structure of the trial was as follows: (1) an instruction indicating that a new trial was about to start appeared on the screen, indicating that participants should press the two response buttons (in the response box) with their two hands and hold them pressed until their response; (2) while they pressed the response buttons, an asterisk appeared in the center of the screen for $500 \mathrm{~ms}$, followed by a blank interval of $300 \mathrm{~ms}$; (3) a video appeared containing the video-distractor and the picture (see Figure 1) and lasted for approximately $500 \mathrm{~ms}$. When the video finished, the image remained still on the last frame until the participant's response; (4) $2000 \mathrm{~ms}$ after the participant's response, the message telling the participant to press the button responses appeared again. Reaction times were registered from the onset of the picture + video presentation to the moment the participant raised her hands off the button box to sign the name of the picture. Stimulus presentation and reaction times were controlled by Psyscope software (Cohen et al., 1993). Participants were videotaped during the experimental session to score for errors. 


\section{RESULTS}

Responses different from the ones designated by the experimenter were considered as production errors and were excluded from the latency analyses. Moreover, those responses in which the participant stopped before signing were considered as hesitations and therefore counted as errors. Two pictures were also excluded because more than $80 \%$ of the participants used a sign different from the one designated by the experimenter (one picture in the Location-Handshape and one in the Location-Movement condition; indicated by an asterisk in the Appendix-Supplementary Material). Finally, signing latencies above or below two standard deviations in each condition were also excluded. Data trimming led to final exclusion of $10 \%$ of the data from the latency analysis.

Median latencies and error rates were analyzed for each phonological condition separately (Handshape-Movement, Location-Handshape, and Location-Movement). Note that using the median instead of the mean is a common practice in the analysis of populations in which a lot of variability and extreme values can be encountered.

In a $2 \times 2$ ANOVA, the phonological relationship (related vs. unrelated) and the group of participants (native vs. non-native) were entered as within participant and between items factors, respectively. The analyses considering the error rates did not reveal any significant results (all $p$ 's $>0.2$ ) and they are not further discussed. Moreover, native and non-native signers did not differ in their overall signing performance. The main effect of group was not significant in any of the conditions explored (all $F$ 's $<1$ ).

Regarding signing latencies (Table 1), participants were slower signing those pictures sharing Handshape and Movement with the video-distractor than the same pictures when the distractor was phonologically unrelated $\left[F_{1(1,22)}=7.47, p<\right.$ 0.05 and $\left.F_{2(1,18)}=4.34, p=0.05\right]$. That is, the HandshapeMovement phonological combination revealed an interference effect. Moreover, the interaction between phonological relatedness and group of participants (Natives vs. Non-natives) was significant in the analysis by participants $\left[F_{1(1,22)}=4.04, p=\right.$ 0.05 and $\left.F_{2(1,18)}=1.29, p=0.27\right]$. Post-hoc comparisons indicated that the non-native group was affected by the HandshapeMovement phonological overlap between the picture and the distractor $\left[F_{1(1,22)}=11.2, p<0.01\right]$, but not the native group $(F<1)$.

For the Location-Handshape condition (LH), there were no significant differences between the signing latencies in the related and the unrelated conditions $\left[F_{1(1,22)}=1.69, p=0.20\right.$ and $\left.F_{2(1,16)}=1.72, p=0.20\right]$. Moreover, as indicated by the lack of interaction with age of acquisition $(F<1)$, neither native nor non-natives were affected by the Location-Handshape phonological overlap.

Finally, we found a main effect of the Location-Movement combination $\left[F_{1(1,22)}=5.61, p<0.05\right.$ and $F_{2(1,16)}=4.41, p<$ 0.05]. Participants were faster signing pictures when sharing the Location and the Movement with the distractor than when signing the same pictures when presented with an unrelated distractor. Both groups of participants benefited from the LocationMovement phonological overlap between target and distractor, as indicated by the lack of interaction between the phonological condition and group of participants $(F<1)$.
Table 1 | Median reaction times (RT) and percentage of errors (\%error) in each phonological condition for the native and non-native group of participants.

\begin{tabular}{|c|c|c|c|c|c|c|c|}
\hline \multicolumn{2}{|c|}{ Type of relationship } & \multicolumn{3}{|c|}{ Natives } & \multicolumn{3}{|c|}{ Non-natives } \\
\hline & & $R T$ & $S D$ & $\%$ Error & $R T$ & $S D$ & $\%$ Error \\
\hline \multirow[t]{3}{*}{$\mathrm{HM}$} & Related & 606 & 224 & 3.8 & 535 & 169 & 8.3 \\
\hline & Unrelated & 596 & 230 & 4.5 & 474 & 142 & 5.8 \\
\hline & HM effect & 10 & & & 59 & & \\
\hline \multirow[t]{3}{*}{$\mathrm{LH}$} & Related & 597 & 263 & 2.8 & 508 & 157 & 2 \\
\hline & Unrelated & 577 & 215 & 2.5 & 491 & 152 & 2.7 \\
\hline & LH effect & 20 & & & 17 & & \\
\hline \multirow[t]{3}{*}{ LM } & Related & 565 & 237 & 4.6 & 449 & 124 & 6.1 \\
\hline & Unrelated & 592 & 256 & 6.5 & 509 & 180 & 3.0 \\
\hline & LM effect & -27 & & & -50 & & \\
\hline
\end{tabular}

HM, Handshape-Movement; LH, Location-Handshape; LM, Location-Movement.

\section{DISCUSSION}

This study aimed to explore the role of the different syllabic units during sign production. Specifically, we tested whether the combination of Location and Movement, suggested by sign language models as the most important syllabic unit, would stand out during on-line LSC sign production in comparison to other parameter combinations.

Our results were clear-cut: both native and non-native signers were faster at signing the intended target only when it was presented together with a distractor that shared the Location and the Movement ${ }^{1}$. In line with previous research (Corina and Knapp, 2006), the present results support the idea that the combination of parameters Location-Movement seems to enjoy a privileged status during sign production, as well as during sign comprehension (e.g., Dye and Shih, 2006). Indeed, linguistic models of sign structure have described Movements and Locations as the main syllabic building blocks (e.g., Sandler, 1987; Corina and Emmorey, 1993; Brentari, 1998) with Handshapes being represented on a separate structural tier (e.g., Sandler, 1993). Although those models were created to describe signs in American Signed Language (ASL), our results and others suggest a more general effect of the Location-Movement combination across the world's signed languages, at least in what concerns Spanish Signed language (Gutierrez, 2008), British Signed Language (Dye and Shih, 2006), and Catalan Signed language. Note, however, that with these results we cannot attribute to the Location-Movement combination the unique status of syllabic unit in signed language. The reason is that finding that the Location-Movement combination influences sign production does not demonstrate that other syllabic structures do not exist in sign language (e.g., Chinchor, 1978). For instance, the Handshape-Movement combination also influenced sign production (although in the opposite direction) of non-natives, suggesting a different impact of the

\footnotetext{
${ }^{1}$ Note that although signing latencies are measured in the picture-signing interference task, both comprehension and production mechanisms are involved when performing such task.
} 
three phonological combinations rather than the unique existence of Location-Movement as syllabic unit. Thus, the interesting question for us is: What is special about the Location-Movement combination in sign language processing? If we consider that the inventory of Locations and Movements within signed languages is significantly smaller than the inventory of Handshapes, one possibility is that particular Locations and Movements appear more frequently in the lexicon than Handshapes do. Indeed, children acquire control of the Location and Movement parameters much earlier than they master Handshapes, which require specialized dexterity of the hands and fingers (e.g., Siedlecki and Bonvillian, 1993; Conlin et al., 2000; Marentette and Mayberry, 2000). Furthermore, there is evidence that when signers make an error, the probability of involving a change in Movement or Location is relatively low $(8 \%)$ compared to the probability of making an error that involves a change in the Handshape (82\%; Hohenberger et al., 2002; see also Orfanidou et al., 2009). Similarly, Location and Movement are less prone to errors than Handshape in aphasic signers (Corina et al., 1992; Corina, 2000). Thus, it could be argued that our results are due to Location and Movement being more strongly represented than Handshape. However, this idea is not longer tenable if we compare the influence of these parameters when presented in isolation or jointly. Many studies have reported a facilitatory effect when Location and Movement are presented jointly, both in sign comprehension and production, and regardless of the age at which sign language was acquired. In contrast, the effect of each parameter when presented in isolation is highly variable. For instance, both inhibitory (Baus et al., 2008; Carreiras et al., 2008; see also, Caselli and Cohen-Goldberg, 2014; for a computational model on the location effects) and facilitatory effects (e.g., Dye and Shih, 2006; Orfanidou et al., 2009) have been reported when in the same task Location was manipulated in isolation. Thus, our results suggest that phonological combinations involving Location-Movement are indeed an important functional unit in lexical access and not just the additive effect of sharing two parameters (Wilbur and Allen, 1991).

Phonological combinations involving Location and Movement in sign languages have been considered to be more perceptually salient than those involving Handshape (e.g., Klima and Bellugi, 1979; Corina and Emmorey, 1993; Hohenberger et al., 2002). For instance, Hildebrant and Corina (2002) asked participants to judge the phonological similarity between a target-sign and surrounding flanker-signs, which could share the HandshapeMovement, the Location-Handshape or the Movement-Location parameters. Native signers rated those flankers that shared the Location-Movement combination more similar to the target than those involving the Handshape. Our results are in line with the idea of Location-Movement being the most salient sub-lexical (syllabic or not) unit in sign production. In this context, accessing the phonological codes composing the picture's corresponding sign would be faster for those signs sharing Location and Movement, since they will be judged as more similar than the other two phonological combinations. This would support the idea that linguistic distinctions are based on salient perceptual distinctions (Corina et al., 2014). Alternatively (but not mutually exclusive), our results could be interpreted as an effect of the frequency with which the parameters co-occur in sign language, with sign-units involving Location and Movement appearing more frequently than those involving Handshape. Our results would be in line with those studies in the spoken modality showing that speakers are faster at naming words containing highfrequency syllables (which they have produced more often) than words containing low-frequency ones (e.g., Carreiras and Perea, 2004; Cholin et al., 2006; Laganaro and Alario, 2006). However, here we cannot exclude the possibility that other sublexical variables, such as the biphone frequency (frequency with which two phonemes co-occur regardless of whether they respect the syllabic boundaries or not), are responsible for the observed effect. In the spoken modality, the speed with which a word is produced is influenced both by the syllabic and the biphone frequency (Vitevitch et al., 2004). Such distinction has not been described in the signed modality, possibly due to the simultaneous perception of parameters within a sign. Thus, whether Location-Movement is the most frequent syllabic unit or just comprises the sequences that co-occur with more probability in the language cannot be determined from the present results. Lee and Goldrick (2008) also argued that speakers are not only sensitive to the frequency with which sub-syllabic sequences occur within a language but also to the strength of association. Importantly, if the language of the speaker determines the preference for one sequence (for instance, in Korean, sequences involving onset-vowels are strongly associated, whereas in English it is vowel-coda sequences which are more associated), it is possible that our results reveal the preference of signers for those sequences strongly associated in sign language, namely Location-Movement sequences. At present, we cannot determine whether the origin of the observed effect stems from Location-Movement being the most salient structure or the phonological sequence more probable in the language, but this opens interesting questions for future studies on phonological processing in signed language.

Finally, regarding the question of how the age of sign language acquisition might influence its phonological processing, we did not find differences between groups for the Location and Movement combination. However, the two groups differed in two aspects. Firstly, there was a tendency for shorter latencies in the non-native group than in the native one. This result was unexpected if we consider previous evidence pointing to less efficient phonological processing in non-native signers (e.g., Gutierrez et al., 2012a). Nevertheless, the fact that such differences were not significant, together with the observation that the non-native signers were overall younger than the native signers and that this is known to have an impact on processing-speed (e.g., Salthouse, 1993), prevent us from making further interpretations. Secondly and more interesting, we only obtained a difference between the two groups for the Handshape-Movement combination. Non-native signers were slower at signing pictures in the presence of the Handshape-Movement phonological distractor than in the presence of an unrelated distractor. This piece of evidence supports the idea that the late acquisition of signs results in subtle differences in sign language processing (Newport, 1990; Mayberry and Eichen, 1991; Neville et al., 1997; Corina and Hildebrandt, 2002; Newman et al., 2002; Carreiras et al., 2008; Morford et al., 2008) often involving a qualitatively different processing of Handshapes (Emmorey et al., 2003; Carreiras et al., 2008; Orfanidou et al., 2009; Best et al., 2010; Gutierrez et al., 
2012a). For instance, Hildebrant and Corina (2002) found that non-native signers judged signs as perceptually more similar when sharing the Handshape than the other parameters, while native signers based their decision on the Movement. However, Handshape cannot be the only explanation for two reasons: (1) a facilitatory effect of Handshape was reported by Baus et al. (2008) while the manipulation of Handshape in combination with Movement led to an interference effect, and (2) if Handshape is the parameter responsible for the pattern of results found for non-natives, similar results would be expected for the other phonological combination involving Handshape, namely the Location-Handshape condition. Considering these and previous findings, the pattern of results reported for non-natives is rather complex, even when more sensitive techniques such as ERPs have been employed (Gutierrez et al., 2012a). For instance, Gutierrez et al. (2012a) found that non-natives were not affected by Handshape relatedness during sign recognition either of signs or non-signs, while previous studies have reported Handshape to be the most salient phonological parameter for late signers (Corina and Hildebrandt, 2002). Thus, at this point, any interpretation of the interference effect observed for HandshapeMovement would be very tentative and premature, but it opens an excellent question to pursue in the future. Importantly, this effect also supports the idea indicated above that two-parameter effects are not just the additive effect of the two single parameters.

\section{CONCLUSION}

In sum, our results provide clear evidence of the special role that certain phonological combinations play in sign language production. Location-Movement is the only phonological combination that enjoys a benefit in processing during sign production.

\section{ACKNOWLEDGMENTS}

This research was supported by the project "LSE_SIGN: Base de datos de parámetros fonológicos de la Lengua de Signos Española" (PSI2008-04016-E/PSIC) from the Ministry of Science and Innovation and the project PSI2012-31448 from the Spanish Government. Cristina Baus was supported by the Intra-European Fellowship (FP7-PEOPLE-2014-IEF) of the Marie Curie Actions. The authors thank all the deaf participants who collaborated in this study. Thanks to the different Deaf Associations in Barcelona (CERECUSOR, CEIR) and especially to Santiago Frigola and Delfina Aliaga for their invaluable help in the contact with the participants.

\section{SUPPLEMENTARY MATERIAL}

The Supplementary Material for this article can be found online at: http://www.frontiersin.org/journal/10.3389/fpsyg. 2014.01254/abstract

\section{REFERENCES}

Aichert, I., and Ziegler, W. (2004). Syllable frequency and syllable structure in apraxia of speech. Brain Lang. 88, 148-159. doi: 10.1016/S0093-934X(03) 00296-7

Alario, F.-X., Ferrand, L., Laganaro, M., New, B., Frauenfelder, U. H., and Segui, J. (2004). Predictors of picture naming speed. Behav. Res. Methods Instrum. Comput. 36, 140-155. doi: 10.3758/BF03195559

Baumann, M. (1995). The Production of Syllables in Connected Speech. Ph.D. dissertation, Nijmegen University.
Baus, C., Gutiérrez-Sigut, E., Quer, J., and Carreiras, M. (2008). Lexical access in Catalan Signed Language (LSC) production. Cognition 108, 856-865. doi: 10.1016/j.cognition.2008.05.012

Best, C., Mathur, G., Miranda, K., and Lillo-Martin, D. (2010). Effects of sign language experience on categorical perception of dynamic ASL pseudosigns. Atten. Percept. Psychophys. 72, 747-762. doi: 10.3758/APP.72.3.747

Boomer, D. S., and Laver, J. D. M. (1968). Slips of the tongue. Br. J. Disord. Commun. 3, 2-12. doi: 10.3109/13682826809011435

Brentari, D. (1990). Theoretical Foundations of American Sign Language Phonology. Unpublished doctoral dissertation, University of Chicago.

Brentari, D. (1998). A Prosodic Model of Sign Language Phonology. Cambridge, MA: MIT Press.

Carreiras, M. (2010). Sign language processing. Lang. Linguist. Compass 4, 430-444. doi: 10.1111/j.1749-818X.2010.00192.x

Carreiras, M., Gutiérrez-Sigut, E., Baquero, S., and Corina, D. (2008). Lexical processing in Spanish Sign Language (LSE). J. Mem. Lang. 58, 100-122. doi: 10.1016/j.jml.2007.05.004

Carreiras, M., and Perea, M. (2004). Naming pseudowords in Spanish: effects of syllable frequency. Brain Lang. 90, 393-400. doi: 10.1016/j.bandl.2003.12.003

Caselli, N. K., and Cohen-Goldberg, A. M. (2014). Lexical access in sign language: a computational model. Front. Psychol. 5:428. doi: 10.3389/fpsyg.2014.00428

Chen, J. Y., Chen, T. M., and Dell, G. (2002). Word-Form encoding in Mandarin Chinese as assessed by the implicit priming task. J. Mem. Lang. 46, 751-781. doi: 10.1006/jmla.2001.2825

Chen, J. Y., and Cherng, R. J. (2013). The proximate unit in Chinese handwritten character production. Front. Psychol. 4:517. doi: 10.3389/fpsyg.2013.00517

Chinchor, N. (1978). "The Syllable in ASL," in Paper Presented at the MIT Sign Language Symposium (Cambridge, MA).

Cholin, J., Levelt, W. J. M., and Schiller, N. O. (2006). Effects of syllable frequency in speech production. Cognition 99, 205-235. doi: 10.1016/j.cognition.2005.01.009

Cohen, J. D., MacWhinney, B., Flatt, M., and Provost, J. (1993). PsyScope: a new graphic interactive environment for designing psychology experiments. Behav. Res. Methods Instrum. Comput. 25, 257-271. doi: 10.3758/BF03204507

Conlin, K. E., Mirus, G. R., Mauk, C., and Meier, R. P. (2000). "The acquisition of first signs: place, handshape, and movement," in Language Acquisition by Eye, eds C. Chamberlain, J. P. Morford, and R. I. Mayberry (Mahwah, NJ: Erlbaum), 51-70.

Corina, D. (1990). Reassessing the role of sonority in syllable structure: evidence from a visual-gestural language. CLS 26, 33-44.

Corina, D. (2000). "Some observations regarding paraphasia in American Sign Language," in The Signs of Language Revisited: An Anthology to Honor Ursula Bellugi and Edward Klima, eds K. Emmorey and H. Lane (Mahwah, NJ: Erlbaum), 493-507.

Corina, D. P., and Emmorey, K. (1993). "Lexical priming in American Sign Language," in Paper Presented at the Linguistic Society of American Conference (Philadelphia, PA).

Corina, D. P., Hafer, S., and Welch, K. (2014). Phonological awareness for American Sign Language. J. Deaf Stud. Deaf Educ. Adv. 19, 530-545. doi: 10.1093/deafed/enu023

Corina, D. P., and Hildebrandt, U. (2002). "Psycholinguistic investigations of phonological structure in American Sign Language," in Modality and Structure in Signed and Spoken Languages, eds R. P. Meier, K. Cormier, and D. QuintoPozos (Cambridge: Cambridge University Press), 88-111.

Corina, D. P., and Knapp, H. P. (2006). "Lexical retrieval in American Sign Language production," in Laboratory Phonology, 8: Varieties of Phonological Competence, eds L. Goldstein, D. Whalen, and C. Best (Berlin: Mouton de Gruyter), 213-239.

Corina, D. P., Poizner, H., Bellugi, U., Feinberg, T., Dowd, D., and O'Grady-Batch, L. (1992). Dissociation between linguistic and nonlinguistic gestural systems: a case for compositionality. Brain Lang. 43, 414-447. doi: 10.1016/0093934X(92)90110-Z

Crompton, A. (1981). Syllables and segments in speech production. Linguistics 19, 663-716. doi: 10.1515/ling.1981.19.7-8.663

Dell, G. S. (1988). The retrieval of phonological forms in production: tests of predictions from a connectionist model. J. Mem. Lang. 27, 124-142. doi: 10.1016/0749-596X(88)90070-8

Dye, M. W. G., and Shih, S. (2006). "Phonological priming in British Sign Language," in Laboratory Phonology, 8: Varieties of Phonological Competence, eds L. Goldstein, D. Whalen, and C. Best (Berlin: Mouton de Grutyer). 
Emmorey, K. (2002). Language, Cognition, and the Brain: Insights from Sign Language Research. Mahwah, NJ: Erlbaum.

Emmorey, K., and Corina, D. (1990). Lexical recognition in sign language: effects of phonetic structure and morphology. Percept. Mot. Skills 71, 1227-1252.

Emmorey, K., McCullough, S., and Brentari, D. (2003). Categorical perception in American Sign Language. Lang. Cogn. Process. 18, 21-45. doi: 10.1080/01690960143000416

Emmorey, K., Mehta, S., and Grabowski, T. J. (2007). The neural correlates of sign and word production. Neuroimage 36, 202-208. doi: 10.1016/j.neuroimage.2007.02.040

Ferrand, L., Segui, J., and Grainger, J. (1996). Masked priming of word and picture naming: the role of syllable units. J. Mem. Lang. 35, 708-723. doi: 10.1006/jmla.1996.0037

Ferrand, L., Segui, J., and Humphreys, G. W. (1997). The syllable's role in word naming. Mem. Cognit. 25, 458-470. doi: 10.3758/BF03201122

Gutierrez, E. (2008). El Papel de Los Parámetros Fonológicos en el Procesamiento de la Lengua de Signos Española. Unpublished doctoral dissertation, University of la Laguna, Tenerife, Spain.

Gutierrez, E., Müller, O., Baus, C., and Carreiras, M. (2012a). Electrophysiological evidence for phonological priming in Spanish Sign Language lexical access. Neuropsychologia 50, 1335-1346. doi: 10.1016/j.neuropsychologia.2012. 02.018

Gutierrez, E., Williams, D., Grosvald, M., and Corina, D. (2012b). Lexical access in American Sign Language: an ERP investigation of effects of semantics and phonology. Brain Res. 1468, 63-83. doi: 10.1016/j.brainres.2012.04.029

Hildebrant, U., and Corina, D. P.(2002). Phonological similarity in American Sign Language. Lang. Cogn. Process. 6, 593-612. doi: 10.1080/01690960143000371

Hohenberger, A., Happ, D., and Leuninger, H. (2002). "Modality dependent aspects of signed language production: evidence from slips of the hands and their repairs in German Sign Language," in Modality and Structure in Signed and Spoken Language, eds R. P. Meier, K. Cormier, and D. Quinto-Pozos (Cambridge: Cambridge University Press), 112-142.

Hosemann, J., Hermann, A., Steinbach, M., Bornkessel-Schlesewsky, I., and Schlesewsky, M. (2013). Lexical prediction via forward models: N400 evidence from German Sign Language. Neuropsychologia 51, 2224-2237. doi: 10.1016/j.neuropsychologia.2013.07.013

Johnston, T., and Schembri, A. (1999). On defining lexeme in a Signed Language. Sign Lang. Linguist. 2, 115-185. doi: 10.1075/sll.2.2.03joh

Klima, E. S., and Bellugi, U. (1979). The Signs of Language. Cambridge, MA: Harvard University Press.

Laganaro, M., and Alario, F.-X. (2006). On the locus of the syllable frequency effect in speech production. J. Mem. Lang. 55, 178-196. doi: 10.1016/j.jml.2006.05.001

Lee, Y., and Goldrick, M. (2008). The emergence of sub-syllabic representations. J. Mem. Lang. 59, 155-168. doi: 10.1016/j.jml.2008.03.002

Levelt, W. J. M., and Wheeldon, L. (1994). Do speakers have access to a mental syllabary? Cognition 50, 239-269.

Mackay, D. G. (1970). Spoonerisms: the structure of errors in the serial order of speech. Neuropsychologia 8, 323-350. doi: 10.1016/0028-3932(70)90078-3

MacSweeney, M, Capek, C. M., Campbell, R., and Woll, B. (2008). The signing brain: the neurobiology of sign language. Trends Cogn. Sci. 12, 432-440. doi: 10.1016/j.tics.2008.07.010

Marentette, P. F., and Mayberry, R. (2000). "Principles for an emerging phonological system: a case study of acquisition of early ASL," in Language Acquisition by Eye, eds C. Chamberlain and J. P. Morford (Nawhah, NJ: Lawrence Erlbaum Associates), 71-90.

Mayberry, R., and Eichen, E. (1991). The long-lasting advantages of learning sign language in childhood: another look at the critical period for language acquisition. J. Mem. Lang. 30, 486-512. doi: 10.1016/0749-596X(91)90018-F

Mayberry, R. I., and Witcher, P. (2006). What Age of Acquisition Effects Reveal About the Nature of Phonological Processing. CRL Technical Reports, Vol. 17, University of California, San Diego, CA.

Mayberry, R. I., and Fisher, S. D. (1989). Looking through phonological shape to lexical meaning: the bottleneck of non-native sign language processing. Mem. Cognit. 17, 740-754.

Morford, J. P., Grieve Smith, A. B., MacFarlane, J., Staley, J., and Waters, G. S. (2008). Effects of language experience on the perception of American Sign Language. Cognition 109, 41-53. doi: 10.1016/j.cognition.2008.07.016

Neville, H., Coffey, S., Lawson, D., Fischer, A., Emmorey, K., and Bellugi, U. (1997). Neural systems mediating American Sign Language: effects of sensory experience and age of acquisition. Brain Lang. 57, 285-308. doi: 10.1006/brln.1997.1739

Newman, A., Bavelier, D., Corina, D., Jezzard, P., and Neville, H. (2002). A critical period for right hemisphere recruitment in American Sign Language processing. Nat. Neurosci. 5, 76-80. doi: 10.1038/nn775

Newport, E. (1990). Maturational constrains on language learning. Cogn. Sci. 14, 11-28. doi: 10.1207/s15516709cog1401_2

Orfanidou, E., Adam, R., McQueen, J. M., and Morgan, G. (2009). Making sense of nonsense in British Sign Language (BSL): the contribution of different phonological parameters to sign recognition. Mem. Cognit. 37, 302-315. doi: 10.3758/MC.37.3.302

Perlmutter, D. (1992). Sonority and syllable structure in American Sign Language. Linguist. Inq. 23, 407-442.

Salthouse, T. A. (1993). Speed and knowledge as determinants of adult age differences in verbal tasks. J. Gerontol. 4, 29-36. doi: 10.1093/geronj/48.1.P29

Sandler, W. (1987). Assimilation and feature hierarchy in American Sign Language. Chic. Linguist. Soc. 23, 266-278.

Sandler, W. (1989). Phonological Representation of the Sign: Linearity and Nonlinearity in American Sign Language. Dordrecht: Foris. doi: $10.1515 / 9783110250473$

Sandler, W. (1993). A sonority cycle in American Sign Language. Phonology 10, 243-280. doi: 10.1017/S0952675700000051

San Jose-Robertson, L., Corina, D. P., Ackerman, D., Guillemin, A., and Braun, A. R (2004). Neural systems for sign language production: mechanisms supporting lexical selection, phonological encoding, and articulation. Hum. Brain Mapp. 23, 156-167. doi: 10.1002/hbm.20054

Schiller, N. O. (1998). The effect of visually masked primes on the naming latencies of words and pictures. J. Mem. Lang. 39, 484-507. doi: 10.1006/jmla.1998.2577

Schiller, N. O., and Costa, A. (2006). Activation of segments, not syllables, during phonological encoding in speech production. Mental Lexicon 1, 231-250. doi: 10.1075/ml.1.2.04sch

Schiller, N. O., Costa, A., and Colomé, A. (2002). "Phonological encoding of single words: in search of the lost syllable," in Papers in Laboratory Phonology, eds C. Gussenhoven and N. Warner (Berlin: Mouton de Gruyter), 35-59.

Selkirk, E. O. (1982). The Syntax of Words. Cambridge, MA: MIT Press.

Siedlecki, T., and Bonvillian, J. D. (1993). Location, handshape, and movement: young children's acquisition of the formational aspects of American Sign Language. Sign Lang. Stud. 78, 31-52. doi: 10.1353/sls.1993.0016

Snodgrass, J. G., and Vanderwart, M. (1980). A standarized set of 260 pictures: norms for name agreement, image agreement, familiarity and visual complexity. J. Exp. Psychol. Hum. Learn. Mem. 6, 174-215.

Stokoe, W. (1960). Sign Language Structure: an Outline of the Visual Communication Systems of the American Deaf. Silver Spring, MD: Linstok Press.

Vitevitch, M. S., Armbrüster, J., and Chu, S. (2004). Sublexical and lexical representations in speech production: effects of phonotactic probability and onset density. J. Exp. Psychol. Learn. Mem. Cogn. 30, 514-529. doi: 10.1037/02787393.30.2.514

Wilbur, R. (1993). "Syllables and segments: hold the movement and move the holds," in Phonetics and Phonology, Vol 3: Current Issues in ASL Phonology, ed G. Coulter (San Diego, CA: Academic Press), 135-166.

Wilbur, R., and Allen, G. D. (1991). Perceptual evidence against internal structure in American Signed Language. Lang. Speech 34, 27-46.

Conflict of Interest Statement: The authors declare that the research was conducted in the absence of any commercial or financial relationships that could be construed as a potential conflict of interest.

Received: 14 April 2014; accepted: 15 October 2014; published online: 13 November 2014.

Citation: Baus C, Gutiérrez E and Carreiras $M$ (2014) The role of syllables in sign language production. Front. Psychol. 5:1254. doi: 10.3389/fpsyg.2014.01254

This article was submitted to Language Sciences, a section of the journal Frontiers in Psychology.

Copyright (C) 2014 Baus, Gutiérrez and Carreiras. This is an open-access article distributed under the terms of the Creative Commons Attribution License (CC BY). The use, distribution or reproduction in other forums is permitted, provided the original author(s) or licensor are credited and that the original publication in this journal is cited, in accordance with accepted academic practice. No use, distribution or reproduction is permitted which does not comply with these terms. 